\title{
Healthy teeth focus on high profile children's TV
}

\author{
Positive messages about healthy teeth have \\ been featured in a high profile children's TV \\ show Hey Duggee. \\ An episode of the programme entitled \\ The Tooth Brushing Badge, which is aimed at \\ children aged two to five, was shown on the \\ CBeebies channel in March 2019 as part of \\ the show's third series. \\ ToothFairyBlog organiser Claire Stevens, \\ Consultant in Paediatric Dentistry and \\ spokesperson for the British Society of \\ Paediatric Dentistry (BSPD) approached the \\ TV show's producers Studio Aka to suggest \\ a tooth brushing theme. Coincidentally, the \\ producers were already considering the topic \\ and were happy to receive the advice. \\ Dr Stevens has two young children who \\ watch the programme and this gave her the
}

idea of reaching millions of children through the show to tell them of the importance of tooth brushing.

After writing to the head of production to see if tooth brushing could become an activity at Hey Duggee's squirrel club, Dr Stevens was invited to submit some content suggestions, working on a script and key messages.

Since being broadcast, the topic of tooth brushing has been trending on social media.

Dr Stevens said: 'The result has been beyond my expectations. News of Hey Duggee's endorsement of tooth brushing spread like wildfire on social media.

'I have read some fantastic comments from parents who are delighted by Hey Duggee's positive influence. Hey Duggee has a cult following among millions due to the inspired

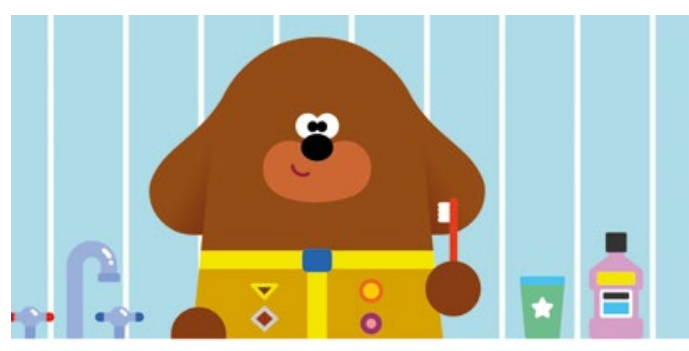

combination of script, music and jokes designed to appeal to both the very young and their parents.

'Now I hope we are going to see many more children engaged with brushing their teeth. Studio Aka and CBeebies have been very supportive in getting out the message that looking after your teeth keeps them sparkling and healthy - and keeps your breath fresh.'

\section{Oral care must be more accessible for patients with learning disabilities}

\section{Dentists are being reminded of their} obligations to provide care and ensure full access for patients with a learning disability in recently issued guidance ${ }^{1}$ from Public Health England (PHE).

PHE's guidance issued on 6 March 2019 sets out information on definitions of learning disabilities, what to notice, making 'reasonable adjustments', entitlement to free NHS dental treatment in England, national policy, barriers to good oral care and accessing dental services for this part of the population, what works at an individual and service level, and resources.

In England it was estimated in 2015 that there were $1,087,100$ people with learning disabilities, including 930,400 adults. However, the number of people with learning disabilities recorded in health and welfare systems is much lower.

The document says existing research has consistently shown that people with learning disabilities have:

- Higher levels of periodontal disease

- Greater gingival inflammation

- Higher numbers of missing teeth

- Increased rates of edentulism

- Higher plaque levels

- Greater unmet oral health needs

- Poorer access to dental services and less preventative dentistry.
PHE's document explains that under the Equality Act 2010, public sector organisations must make reasonable changes in their approach or provision to ensure that services are accessible to disabled people as well as everybody else.

Reasonable adjustments can mean alterations to buildings by providing lifts, wide doors, ramps and tactile signage and extra time allowed for appointments, but can also mean changes to policies, procedures and staff training to ensure that services work equally well for people with learning disabilities.

An example given is that people with learning disabilities might need clear, simple and repeated explanations of what is happening, and of treatments to be followed, help with appointments and help with managing issues of consent in line with the Mental Capacity Act.

The document's authors acknowledge this issue is not straight forward and say: 'It can be challenging to provide dental treatment to people who struggle to understand what is being done and may be uncooperative.

'Many dentists are unconfident about interacting with people with learning disabilities and some are unwilling to treat them. Dental practitioners have cited lack of knowledge and expertise in this area as reasons for this. Evidence suggests that poor attitudes of dental staff can be a barrier to people with learning disabilities using dental services.'

There needed to be sufficient time to explain what is happening during a consultation using easy language and time for the individual to process this, so providing longer appointments was a common and important reasonable adjustment, said the authors.

The guidance includes details of easy-read and accessible resources that can be used to help people understand about good oral care and dental services.

PHE says there seems to be a need for better learning disability training for dental care staff and this should extend to the wider staff team.

The BDA welcomed the guidance and its Chair of the England Community Dental Services Committee, Charlotte Waite, said: 'For too long, the oral health needs of people with learning disabilities have taken a back seat.

'Part of the problem is that commissioning decisions to cater for the needs of these patients are often inadequate because they are not informed by robust oral health needs assessments. The situation is exacerbated by an ever-decreasing number of dentists in community dental services.'

\section{References}

1. Public Health England. Oral care and people with learning disabilities. 2019. Available at https://www.gov.uk/government/publications/oral-care-and-people-with-learning-disabilities (accessed March 2019). 